\title{
LIMITE MÁXIMO DA LEI DE RESPONSABILIDADE FISCAL COM DESPESAS DE PESSOAL: ESTUDO DE CASO DOS ESTADOS BRASILEIROS
}

\section{LIMITATION OF THE FISCAL RESPONSIBILITY LAW WITH THE STAFF PAYMENT SHEET: CASE STUDY OF THE BRAZILIAN STATES}

\author{
Abimael de Jesus Barros Costa ${ }^{1}$ \\ Thayanne Costa da Silva ${ }^{2}$ \\ Alana Alves da Silva ${ }^{3}$ \\ Raquel Pereira Pinori ${ }^{4}$ \\ Marco Aurélio Barros Borges 5 \\ Debora de Sousa dos Santos ${ }^{6}$
}

\begin{abstract}
Resumo
O objetivo deste estudo foi verificar o que os estados que ultrapassaram o limite máximo de gastos com pessoal, permitidos pela LRF, estão colocando em prática para administrar sua despesa com pessoal. $\mathrm{O}$ trabalho foi desenvolvido através de um estudo de caso com metodologia exploratória e descritiva. Ao analisar a despesa dos estados, foi possível observar que os estados Tocantins, Paraíba, Rio Grande do Norte, Acre e Mato Grosso lideram o ranking de gastos com pessoal e estão acima do limite máximo permitido pela LRF, o que os torna objeto desse estudo de caso. Conclui-se que os estados abordados, apesar de estarem acima do limite imposto pela LRF para gasto com pessoal, estão implementando medidas para adequar seus gastos, como exemplo, contratando auditorias independentes para revisão da folha de pagamento e retornar às exigências da Lei de Responsabilidade Fiscal; já é visível o efeito dessas medidas em alguns deles.
\end{abstract}

Palavras-chave: despesa com pessoal. Lei de Responsabilidade Fiscal. prestação de contas.

\begin{abstract}
The objective of this study was to verify that the states that exceeded the maximum limit of personnel expenses, allowed by the LRF, are putting into practice to manage their expenditure with personnel. The work was developed through a case study with exploratory and descriptive methodology. When analyzing state expenditure, it was possible to observe that the states Tocantins, Paraíba, Rio Grande do Norte, Acre and Mato Grosso lead the ranking of personnel expenses and are above the maximum limit allowed by the LRF, which makes them the object of this study of case. It is concluded that the states addressed, although they are above the limit imposed by the LRF for personnel expenses, are implementing measures to adjust their expenses, such as contracting independent audits for payroll review, and to return the requirements of the Liability Law And the effect of these measures is already visible in some of them.
\end{abstract}

Key-words: personnel expenses. Fiscal Responsibility Law. accountability

\footnotetext{
Doutor em Engenharia de Transportes, área Economia dos Transportes, no PPGT do Departamento de Engenharia Civil e Ambiental, Mestre em Contabilidade. Professor do Departamento de Ciências Contábeis e Atuariais e do Programa de Pósgraduação em Ciências Contábeis (PPGCont) da Universidade de Brasília (UnB) E-mail: acosta@unb.br

Mestra em Mensuração Contábil pela Universidade de Brasília (UnB), bacharela em Ciências Contábeis e Atuariais pela Universidade de Brasília (UnB). E-mail: thayanne.costa.tc@gmail.com

${ }^{3}$ Bacharel em contabilidade do Departamento de Ciências Contábeis e Atuariais da (UnB). E-mail: alana.silva@stf.jus.b

${ }^{4}$ Bacharel em contabilidade do Departamento de Ciências Contábeis e Atuariais da (UnB). E-mail: raquelppinori21@gmail.com

5 Bacharel em contabilidade do Departamento de Ciências Contábeis e Atuariais da (UnB). E-mail: mabb123@gmail.com

${ }^{6}$ Bacharel em Contabilidade pelo Departamento de Ciências Contábeis e Atuárias da (UnB). E-mail: debora.sousa.s@hotmail.com
}

Recebido em: 20 de setembro de 2017. Artigo aceito em 24 de junho de 2019. 


\section{COSTA; SILVA; ALVES DA SILVA; PINORI; BORGES; SANTOS}

\section{Introdução}

As receitas arrecadadas pelo Estado devem ser utilizadas de forma eficiente e eficaz. Para que tal utilização não seja feita de forma incorreta, leis são estabelecidas para orientar e limitar tais gastos. A Lei Complementar n. 101, de 4 de maio de 2000, conhecida como Lei de Responsabilidade Fiscal (LRF), estabelece, em regime nacional, parâmetros a serem seguidos relativos ao gasto público de cada ente federativo brasileiro. Dentre outros assuntos, a LRF traz dispositivos que delimitam a criação e expansão das despesas com pessoal, como, por exemplo, a necessidade de autorização da Lei de Diretrizes Orçamentárias para o aumento da despesa.

A LRF contribui para o estabelecimento de um ambiente adequado de controle, o que, segundo Zonatto, Rodrigues Junior e Toledo Filho (2014), proporciona informações mais precisas, tempestivas e oportunas aos gestores, assegurando, assim, um planejamento que vai de encontro aos objetivos do gestor público para determinado período.

A prestação de contas é uma medida de transparência que visa controlar e fiscalizar os recursos da União para que não haja desperdício ou desvios, pois, ao se tratar de verba pública, os valores são transferidos ao Estado na confiança de serem utilizados para os fins determinados. A conta de despesa com pessoal engloba-se no âmbito dos valores no qual o gestor público deve ter atenção em sua prestação de contas; fazem parte dessa rubrica: despesas com pessoal ativo, inativo e pensionista, vencimentos e vantagens, subsídios, reformas e pensões, adicionais, gratificações, horas extras, encargos sociais e contribuições recolhidas pelo ente às entidades de previdência.

A LRF tornou obrigatório o acompanhamento contínuo da despesa com pessoal nas três esferas de governo (União, Estados, Municípios e Distrito Federal). Todo quadrimestre cada ente federativo elabora o Relatório de Gestão Fiscal (RGF) evidenciando os montantes da despesa total com pessoal e outros. Contudo, alguns Estados permanecem ultrapassando o limite máximo para gasto com pessoal estabelecido pela Lei de Responsabilidade Fiscal. Assim, surge o seguinte questionamento de pesquisa: De que forma os Estados que ultrapassaram o limite máximo de gasto com pessoal estão atuando para administrar seus gastos com a folha?

O presente estudo de caso tem como objetivo geral verificar o que os Estados com os 
maiores gastos com pessoal estão adotando como medida para reduzir seus gastos e voltar ao limite permitido pela LRF. Nossos objetivos específicos envolvem realizar uma análise histórica dos gastos com pessoal dos Estados em questão, identificando as sanções previstas, assim como as medidas tomadas pelo gestor do Estado.

A despesa com pessoal é um assunto recorrente nos noticiários e estudos, seja pelo anseio do controle social com foco na transparência do tema ou pela falta de gestão dos governantes quanto ao controle dessa conta. Dessa forma, com as mudanças relevantes da LRF, acompanhar os limites para as referidas despesas torna-se importante no âmbito do estudo do controle no setor público.

Santolin, Jayme Júnior e Reis (2009) afirmam que as decisões de gastos com pessoal podem ser utilizadas como indicador de aprovação populacional, o que, por sua vez, pode acarretar a permanência ou a troca do partido que detém o poder local nas eleições. Assim, colabora com a importância de se estudar e acompanhar a qualidade da administração do gestor público por esse indicador.

Em municípios muito pequenos e com baixa geração de renda, geralmente o poder municipal representa o principal empregador local. Eventualmente a folha de pessoal, mais do que servir apenas a interesses internos, pode ser central para garantir renda mínima à parcela da população local.

Existem vários estudos relacionados aos gastos com pessoal e essa quantidade aumentou consideravelmente depois de imposta a LRF. Pode-se citar trabalhos de diversos autores, como o estudo de Santolin, Jayme Júnior e Reis (2009), que analisou os possíveis impactos da lei no comportamento das despesas dos municípios de Minas Gerais, bem como o estudo da composição e a evolução das despesas com pessoal do estado de Santa Catarina de 2000 a 2011, realizado por Souza e Platt Neto (2012).

O presente estudo mostra-se atual por abordar um problema cada vez mais comum em várias unidades federativas. Assim, a pesquisa apresenta como a gestão de cada Estado está lidando, dentro desse contexto, para melhorar a saúde financeira da sua localidade e respeitar os limites da LRF.

Este trabalho está estruturado da seguinte forma: nesta seção é apresentada a introdução ao tema, problema, objetivo e justificativa do estudo. Na seção seguinte, é realizada uma revisão da literatura sobre a despesa com pessoal e sobre a prestação de contas. Na terceira seção, são apresentados os procedimentos metodológicos adotados na pesquisa. 
$\mathrm{Na}$ quarta, é realizada a apresentação e análise dos dados. E, finalmente, na última seção, são feitas as considerações finais sobre o estudo.

\section{REFERENCIAL TEÓRICO}

\subsection{DESPESA PÚBLICA}

Lima e Castro (2009) definem a despesa pública como os gastos do governo para manter em funcionamento os serviços públicos; assim, dentro da despesa se encontram as autorizações para gastos com as várias atribuições e funções governamentais. As despesas públicas são a distribuição e emprego das receitas para custeio dos setores governamentais e para investimentos. De acordo com Giacomoni (2012), a despesa pública pode ser classificada de acordo com a norma geral e de acordo com a norma federal, conforme abaixo.

Na norma geral, as classificações são detalhadas de acordo com a Lei n $4320 / 64$ e suas alterações; assim, as classificações são:

a) Institucional: também chamada de departamental, seu objetivo é a evidenciação das unidades administrativas que executarão a despesa. Ela possui duas categorias - órgão e unidade orçamentária.

b) Funcional: fornece base para apresentação de dados e estatísticas sobre os gastos públicos nos segmentos das organizações do Estado. É dividida em função e subfunção.

c) Programas: demonstra o resultado final do trabalho do governo para a sociedade. É dividida em programa, projeto, atividade e operações especiais.

d) Natureza: é uma adaptação das categorias e contas das classificações econômica e por elementos. É dividida em categorias econômicas, grupos, modalidades de aplicação e elementos.

A norma federal descreve as características e finalidades da despesa de acordo com dois indicadores: de uso e de resultado primário. A execução da despesa ocorre através dos estágios de empenho, liquidação e pagamento. A despesa com pessoal é uma despesa corrente pública que é relacionada à manutenção das atividades governamentais.

\subsection{DESPESA COM PESSOAL}

Devido à situação econômica que o país enfrenta, as variações dos gastos no setor 


\section{COSTA; SILVA; ALVES DA SILVA; PINORI; BORGES; SANTOS}

público têm recebido cada vez mais atenção dos cidadãos brasileiros. Essa cultura de acompanhamento das contas públicas fortalece o controle social, principalmente em um grupo de despesa tão significativo na prestação dos serviços públicos à sociedade.

De acordo com Correia, Flammarion e Valle (2001, p. 80), “[...] a finalidade principal do Poder Público, como se sabe, é atender ao interesse da sociedade, não só regulando e medindo as relações, mas também promovendo aquilo que se defina constitucionalmente como serviço a ser por ele prestado - serviço público"; a partir daí, justifica-se a necessidade desse dispêndio.

A Lei Complementar $\mathrm{n}^{\circ}$ 101, a partir do seu artigo 18, define despesas de pessoal da seguinte forma:

\footnotetext{
Art. 18. Para os efeitos desta Lei Complementar, entende-se como despesa total com pessoal: o somatório dos gastos do ente da Federação com os ativos, os inativos e os pensionistas, relativos a mandatos eletivos, cargos, funções ou empregos, civis, militares e de membros de Poder, com quaisquer espécies remuneratórias, tais como vencimentos e vantagens, fixas e variáveis, subsídios, proventos da aposentadoria, reformas e pensões, inclusive adicionais, gratificações, horas extras e vantagens pessoais de qualquer natureza, bem como encargos sociais e contribuições recolhidas pelo ente às entidades de previdência. (Brasil, 2000b).
}

A realização da despesa de pessoal obedece a todas as etapas constantes na Lei 4.320/64, no que diz respeito ao empenho, liquidação e pagamento, observados os critérios e procedimentos constitucionais de tais fases. Além disso, o gestor público elabora as peças instrumentais imposta em lei. São elas: o Plano Plurianual (PPA), que estabelece as diretrizes, os objetivos e as metas da administração pública para as despesas de capital e outras delas decorrentes e para as despesas relativas aos Programas de Duração Continuada (art. 165, $\S 1^{\circ}$ da CF); a Lei de Diretrizes Orçamentária (LDO), que estabelece as metas e prioridades da administração pública, incluindo as despesas de capital para o exercício financeiro subsequente, que orienta a elaboração da Lei Orçamentária Anual (LOA) e dispõe sobre as alterações na legislação tributária (art. $165, \S 2^{\circ}$ da $\mathrm{CF}$ ); e a Lei Orçamentária Anual, que estima a receita e fixa a despesa da União (art. 165, § $8^{\circ}$ da CF).

Destacam-se, de acordo com o Manual de Contabilidade Aplicada ao Setor Público (MCASP), elaborado pela Secretaria do Tesouro Nacional (STN), os valores dos contratos de terceirização de mão de obra que se referem à substituição de servidores e empregados públicos contabilizados como “outras despesas de pessoal”. 


\subsection{PRESTAÇÃO DE CONTAS}

Segundo o artigo 37 da Constituição Federal (CF) de 1988, a administração pública direta e indireta dos poderes da União, dos Estados, do Distrito Federal e dos Munícipios deverão obedecer aos princípios da legalidade, impessoalidade, moralidade, publicidade e eficiência.

Dentre tais princípios, o princípio da publicidade tem relação com o artigo $5^{\circ}$ da $\mathrm{CF}$. Segundo o artigo proposto, todo cidadão tem direito a adquirir dos órgãos públicos informações de seu interesse (particular ou coletivo) nos prazos da lei, sob pena de responsabilidade para os casos em que o sigilo não é imprescindível à segurança da sociedade e do Estado.

Macêdo et al. (2014) destacam o papel do controle interno na execução dos planos e projetos dos gestores públicos, de forma a acompanhar o desenrolar dos processos, redirecionando os passos do ente quando necessário, evitando dano ao erário, além de propiciar a realização de um feedback ao analisar a eficiência e eficácia atingidas. O que vai de encontro com a ideia de Platt Neto et al. (2007), pois essas informações divulgadas tornam-se um mecanismo para que a população tenha direito de conhecer os atos praticados na administração pública e participar do controle dos gastos públicos derivado do exercício do poder democrático.

A prestação de contas também é citada na Constituição. O artigo 70 define que é obrigado a prestar contas “[...] qualquer pessoa física ou jurídica, pública ou privada, que utilize, arrecade, guarde, gerencie ou administre dinheiros, bens e valores públicos ou pelos quais a União responda, ou que, em nome desta, assuma obrigações de natureza pecuniária".

Com isso, faz-se necessário prestar contas para que seja observada a utilização da verba pública, de forma consciente e eficiente, evitando-se custos desnecessários e até mesmo desvio das verbas públicas.

\subsection{LEI DE RESPONSABILIDADE FISCAL}

A Lei Complementar $n^{\circ} 101$, de 04 de maio de 2000, conhecida como a Lei de Responsabilidade Fiscal, ou simplesmente por sua sigla, LRF, veio para regulamentar o artigo 169 da Constituição Federal. Ela estabelece padrões para a gestão de recursos e 


\section{COSTA; SILVA; ALVES DA SILVA; PINORI; BORGES; SANTOS}

limites aos gastos públicos, em todas as esferas de governo. A LRF busca o equilíbrio das contas públicas de forma que essas cumpram as metas de resultado entre receitas e despesas, bem como a obediência aos limites e condições estabelecidos.

A transparência na gestão pública, mediante a prestação de contas, é outro quesito que se almeja conseguir, visto que obriga administradores a divulgar relatórios e demonstrativos a fim de garantir a comprovação dos gastos. É uma espécie de código de conduta para os administradores públicos.

Dentre os pontos de destaque está a fixação de limites para a despesa com pessoal. A despesa total com pessoal é definida no artigo 18 da LRF, que indica o somatório dos gastos do ente da Federação com ativos, inativos e pensionistas, relativos a mandatos eletivos, cargos, funções ou empregos, civis e militares e de membros do Poder, com quaisquer espécies remuneratórias, tais como vencimentos e vantagens, fixas e variáveis, subsídios, proventos da aposentadoria, reformas e pensões, inclusive adicionais, gratificações, horas extras e vantagens pessoais de qualquer natureza, bem como encargos sociais e contribuições recolhidas pelo ente às entidades de previdência. Quando há superação dos limites de gastos de pessoal, são previstas punições administrativas e penais que recaem sobre o ente estadual, municipal ou federal, independentemente do Poder. Dentre as sanções/penalidades, estão:

a) Proibição de receber transferências voluntárias, contratar operações de crédito e de obter garantias (LRF, art. $23, \S 3^{\circ}$ );

b) Nulidade do ato (LRF, art. 21); Reclusão de um a quatro anos (Lei n ${ }^{\text {o }}$ 10.028/2000, art. $\left.2^{\circ}\right)$.

c) Cassação do mandato (Decreto-Lei ${ }^{\circ} 201$, art. $4^{\circ}$, inciso VII).

A LRF também ajuda na melhor prestação de contas dos Estados e Municípios. Camargo e Sehnem (2010) constataram em seus estudos que, após a Lei, houve um controle maior na aplicação e destinação dos recursos arrecadados e recebidos em Santa Catarina. Os gastos dos exercícios futuros também foram tratados com maior cuidado para que não fossem comprometidos com investimentos e contas a pagar.

\subsection{RELATÓRIO DE GESTÃO FISCAL}

O Relatório de Gestão Fiscal (RGF) é um dos instrumentos de transparência da gestão fiscal. Nele estarão contidos demonstrativos comparativos com os limites de que trata a 


\section{COSTA; SILVA; ALVES DA SILVA; PINORI; BORGES; SANTOS}

LRF, dos seguintes montantes:

a) despesa total com pessoal, evidenciando as despesas com ativos, inativos e pensionistas;

b) dívida consolidada;

c) concessão de garantias e contra garantias; e

d) operações de crédito.

São obrigados a emitir o Relatório de Gestão Fiscal os Estados, o Distrito Federal e os Municípios. Na esfera estadual, estão compreendidos o Poder Legislativo (incluído o Tribunal de Contas do Estado), o Poder Judiciário, o Poder Executivo, o Ministério Público Estadual.

Conforme disposto na LRF, ao final de cada quadrimestre, os titulares de Poderes e órgãos emitirão o Relatório de Gestão Fiscal para os últimos 12 meses. Este deverá ser publicado e disponibilizado ao acesso público, inclusive em meios eletrônicos, até trinta dias após o encerramento do período a que corresponder.

Caso o relatório não seja divulgado dentro dos prazos e condições estabelecidos em lei, o ente da Federação ficara impedido de receber transferências voluntárias e contratar operações de crédito, exceto as destinadas ao refinanciamento do principal atualizado da dívida mobiliária, até que a situação seja regularizada. $\mathrm{O}$ agente público que der causa à não divulgação também poderá ser punido com multa de trinta por cento de seus vencimentos.

\subsubsection{DEMONSTRATIVO DA DESPESA COM PESSOAL}

O demonstrativo da despesa com pessoal é parte integrante do Relatório de Gestão Fiscal (RGF) e deverá ser elaborado pelos poderes e órgãos com poder de autogoverno, tais como o Poder Executivo, os órgãos dos Poderes Legislativo e Judiciário, o Tribunal de Contas e o Ministério Público.

Conforme o Manual de Demonstrativos Fiscais (2014), o principal objetivo deste demonstrativo é a transparência com relação às despesas com pessoal de cada um dos poderes e órgãos com autonomia administrativa, orçamentária e financeira conferida na forma da Constituição, notadamente quanto à adequação aos limites de que trata a Lei de Responsabilidade Fiscal (LRF).

Um aspecto importante no que diz respeito aos gastos com pessoal é a grande 


\section{COSTA; SILVA; ALVES DA SILVA; PINORI; BORGES; SANTOS}

importância atribuída às metas quantitativas, como pode ser observado na determinação de percentuais máximos possíveis para estes gastos por ente político (LUQUE; SILVA, 2004).

Não são consideradas outras variáveis, tais como a eficiência ou o tamanho do Estado ou Município. Os limites percentuais têm como base a receita corrente líquida (RCL). São eles:

a) Limite máximo (ou limite legal): como pode-se deduzir, é o limite que não poderá ser ultrapassado pelo ente em cada período de apuração. Os percentuais máximos variam de acordo com o nível de governo, conforme Quadro 1. Caso tal limite seja descumprido, o respectivo ente terá o prazo de até dois quadrimestres para a adoção de medidas que visem à recondução ao limite, ou seja, deverá diminuir os seus gastos com pessoal. Se não alcançar a redução neste período, sofrerá uma série de restrições. Enquanto perdurar o excesso, o ente não poderá: receber transferências voluntárias; obter garantia, direta ou indireta, de outro ente; e contratar operações de créditos.

Quadro 1 - Percentuais máximos para cada ente

\begin{tabular}{|l|l|l|l|l|l|}
\hline \multicolumn{1}{|c|}{ Ente } & \multicolumn{1}{|c|}{ Executivo } & \multicolumn{1}{c|}{ Legislativo } & \multicolumn{1}{c|}{ Judiciário } & $\begin{array}{c}\text { Ministério } \\
\text { Público }\end{array}$ & TOTAL \\
\hline UNIÃO & 40,9 & 2,5 & 6,0 & 0,6 & 50,0 \\
\hline ESTADOS/DF & 49,0 & 3,0 & 6,0 & 2,0 & 60,0 \\
\hline MUNICÍPIOS & 54,0 & 6,0 & - & - & 60,0 \\
\hline
\end{tabular}

Fonte: Manual de Demonstrativos Fiscais (BRASIL, 2015).

b) Limite prudencial: trata-se de um limite intermediário para a despesa com pessoal, que equivale a 95\% do limite máximo legal do poder ou órgão. Caso o ente ultrapasse o limite prudencial ficará sujeito a algumas restrições que impliquem em aumento de despesa com pessoal, tais como o impedimento de: contratação de hora-extra; criação de cargo, emprego ou função; concessão de vantagem, aumento ou reajuste da remuneração, dentre outros.

c) Limite de alerta: equivale a $90 \%$ do limite máximo legal do poder ou órgão. Quando o Tribunal de Contas competente constatar que o ente ultrapassou este limite, deverá alertar o poder ou órgão.

\section{PROCEDIMENTOS METODOLÓGICOS}

O trabalho foi desenvolvido através de metodologia descritiva, por se caracterizar como uma pesquisa descritiva, que tem como objetivo primordial a descrição das características de determinada população ou fenômeno. A pesquisa possui um caráter 


\section{COSTA; SILVA; ALVES DA SILVA; PINORI; BORGES; SANTOS}

exploratório, pois busca proporcionar uma maior familiaridade com o objeto a ser estudado, fazendo uma análise relacionando as vantagens, os custos, a aplicabilidade e as funções de um determinado produto ou processo (GIL,2002)

Este estudo foi realizado por meio de análise dos gastos com pessoal dos Estados que ultrapassaram o limite máximo estabelecido pela LRF para responder a seguinte questão central: De que forma os Estados que ultrapassaram o limite máximo de gasto com pessoal estão atuando para administrar seus gastos com a folha? O principal instrumento de pesquisa utilizado foi a captação de base de dados de despesa com pessoal dos Estados, que é disponibilizada no sítio do Sistema de Informações Contábeis e Fiscais do Setor Público Brasileiro (SICONFI) do Tesouro Nacional, com o objetivo de fomentar a análise e o trabalho do auditor social.

Ao analisar a despesa dos Estados, foi possível observar que existem cinco Estados que ultrapassam o limite máximo de gastos com pessoal estabelecido pela LRF, são eles: Tocantins, Paraíba, Rio Grande do Norte, Acre e Mato Grosso. A partir desse ponto, iniciou-se uma análise para buscar, através de notícias e dados, as medidas que estes Estados estão tomando para voltar ao limite permitido pela lei. Também foi realizada uma análise da evolução histórica dos seus gastos com pessoal, à procura do estopim dos problemas com gasto com a folha e de fatos que justificassem os gastos acima do limite máximo.

\section{RESULTADOS, ANÁLISES E DISCUSSÃO}

\subsection{LIMITES DO RGF E GASTOS COM PESSOAL DOS ESTADOS}

Por meio do Sistema de Informações Contábeis e Fiscais do Setor Público Brasileiro (SICONFI), é possível realizar a comparação do indicador gasto com pessoal que faz parte do Relatório de Gestão Fiscal. Nessa ferramenta, foram analisados os gastos do $1^{\circ}$ quadrimestre de 2016 na esfera do Poder Executivo Estadual. Ao comparar os 26 Estados brasileiros e o Distrito Federal, foi constatado que apenas nove Estados estariam dentro do limite prudencial de gastos permitido pela LRF, correspondendo a $33,33 \%$ dos estados.

Seguindo a ordem dos limites estabelecidos pela LRF, os Estados em verde representam aqueles que tiveram o gasto até o limite prudencial, os em laranja estão acima do limite prudencial até o limite máximo, enquanto os Estados em vermelho representam aqueles 
que ultrapassaram o limite máximo permitido, como está representado no mapa a seguir:

Figura 1 - Mapa Fiscal - situação do cumprimento dos limites da LRF por Estado no $1^{\circ}$ quadrimestre de 2016

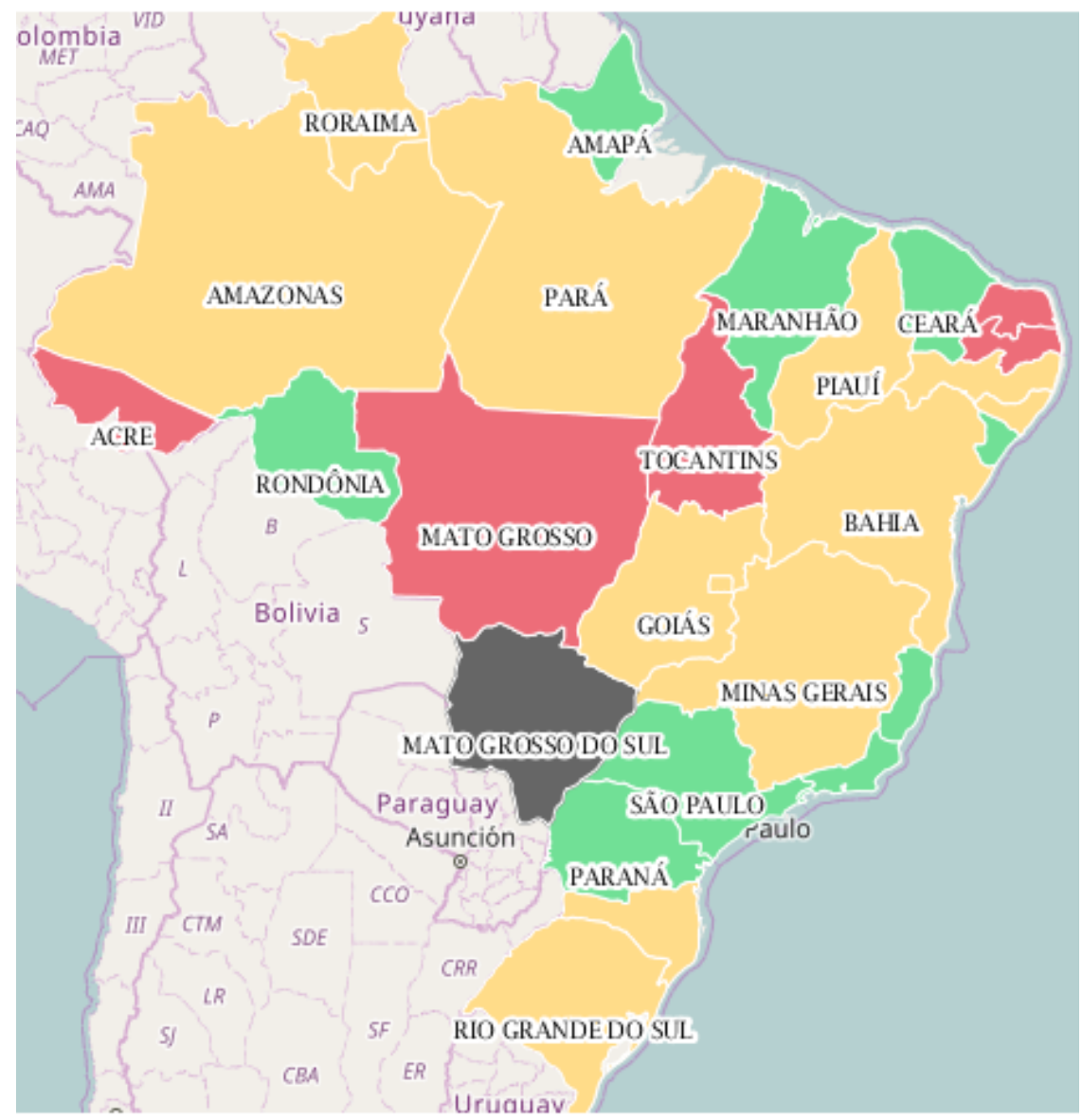

Fonte: SICONFI (2016)

Com a análise do mapa, percebe-se que cinco Estados brasileiros estão acima do limite máximo de pessoal permitido ao Poder Executivo Estadual na LRF (49\%); dentre eles, destaca-se aqui o que os torna objeto do presente estudo. Estes dados estão evidenciados na Tabela 1.

Tabela 1 - Estados que se apresentam acima do limite máximo da LRF no $1^{\circ}$ quadrimestre de 2016

\begin{tabular}{|lccc|}
\hline Estado & DTP (R\$ bilhões) & RCL (R\$ bilhões) & \% \\
\hline Tocantins & 3,39 & 6,44 & $52.66 \%$ \\
\hline Paraíba & 4,15 & 7,95 & $52.17 \%$ \\
\hline Rio Grande do Norte & 4,14 & 8,04 & $51.45 \%$ \\
\hline Acre & 1,98 & 3,91 & $50.59 \%$ \\
\hline Mato Grosso & 6,16 & 12,21 & $50.46 \%$ \\
\hline
\end{tabular}

Fonte: elaborada segundo dados constantes no SICONFI (2016).

Revista Eletrônica Gestão e Serviços v.10, n. 1, pp. 2556 - 12581aneiro/Junho 2019.

ISSN Online: 2177-7284 e-mail: regs@ metodista.br 
Nota: despesa total com pessoal (DTP); receita corrente líquida (RCL); \% da despesa total com pessoal. Valle e Torres (2008) realizaram um estudo a respeito dos impactos da LRF sobre a despesa com pessoal dos Estados desde sua promulgação, em 2000, até o ano de 2006. Uma das conclusões dos autores foi a de que os Estados que apresentavam tendências ao descumprimento dos limites estabelecidos pela LRF eram Paraíba e Rio Grande do Norte, tendo em vista que àquela época já estavam acima do limite prudencial. Dessa forma, conclui-se que tais Estados possuem historicamente dificuldades em se manter dentro dos limites legais.

Nesta pesquisa, daremos foco aos governos dos seguintes Estados: Tocantins, Paraíba, Rio Grande do Norte, Acre e Mato Grosso, que, conforme Tabela 1, são os Estados que atualmente possuem os maiores gastos com despesas de pessoal do Brasil, ultrapassando inclusive o limite máximo.

\subsection{ANÁLISE HISTÓRICA E MEDIDAS TOMADAS PELOS ESTADOS}

A análise histórica dos Estados em questão foi realizada do $1^{\circ}$ quadrimestre de 2011 ao $1^{\text {o }}$ quadrimestre de 2016. Buscou-se analisar a relação entre a despesa total com pessoal e o aumento da receita corrente líquida.

Os dados foram extraídos do portal Compara Brasil, que possui livre acesso aos dados sobre as finanças públicas nos três níveis de governo. A pesquisa possui como foco o Poder Executivo dos Estados, cujo limite da despesa com pessoal constante na LRF é de $49 \%$ da receita corrente líquida.

Por meio de análise da série histórica do Estado, será possível verificar em quais períodos ocorreram descumprimento da lei em consonância com as medidas que foram tomadas para a contenção dos gastos.

\subsubsection{TOCANTINS}

Gráfico 2 - Gasto com pessoal sobre a receita corrente líquida (\%) do Governo do Estado do Tocantins 


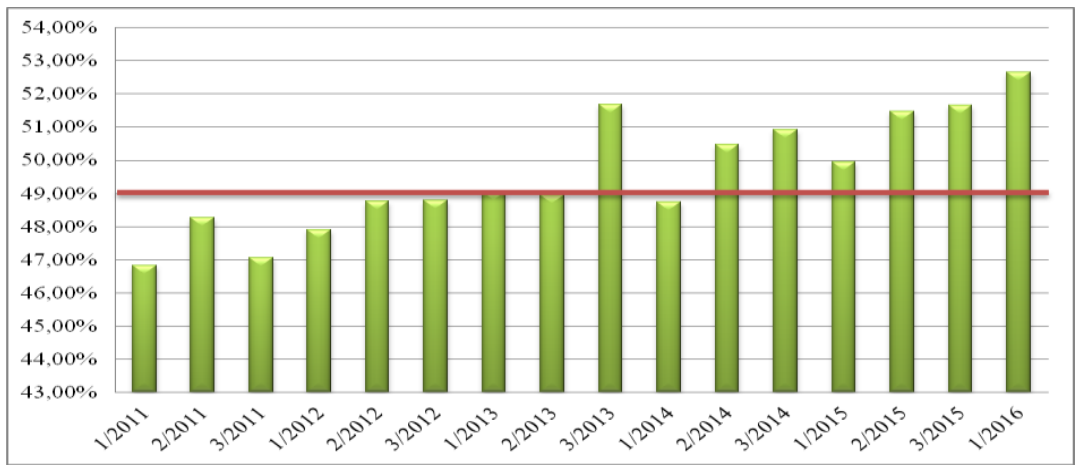

Fonte: elaborado segundo dados constantes no portal Compara Brasil (2016).

O Tocantins vem apresentando uma série de oscilações ao longo do tempo no que se refere à porcentagem de gastos com pessoal na composição da receita líquida. É possível perceber que, com exceção do $1^{\circ}$ quadrimestre de 2014 , a partir do $3^{\circ}$ quadrimestre de 2013, o Estado se manteve permanentemente acima do limite máximo previsto na LRF.

Essa situação traz uma série de consequências. Além das sanções previstas na Lei de Responsabilidade Fiscal, o Estado vem enfrentando descontentamento geral dos servidores. O atraso constante no pagamento dos salários fez com que ocorressem inúmeras paralizações em vários segmentos do funcionalismo público.

Ultrapassar o máximo previsto também fez com que o Tocantins implementasse medidas não populares a fim de reduzir esse percentual. Ao pesquisar sobre a situação, foi possível observar que o atual governador está enfrentando dificuldades na implementação dessas medidas, inclusive da oposição ao seu governo. Em 2015, foi implementado um pacote visando aumentar a arrecadação de impostos, mas a medida impopular causou revolta de políticos e empresários, sendo acusada de inconstitucionalidade e tramitando no Tribunal de Justiça do Estado.

Também foram efetivadas medidas denominadas como "Economia de Guerra", que envolvem o racionamento e enxugamento dos gastos ao máximo.

Além disso, Medidas Provisórias (MP) e Decretos foram instituídos em busca da redução dos gastos com pessoal. A MP $\mathrm{n}^{\circ} 12$, de 5 de agosto de 2013, reestruturou a organização do Poder Executivo e extinguiu milhares de cargos comissionados, além de reduzir os salários dos ocupantes de cargos comissionados em $10 \%$. O Decreto $\mathrm{n}^{\circ}$ 5.184, de $1^{\circ}$ de janeiro de 2015, criou a Comissão de Análise de Impacto de Pessoal sobre os Recursos Financeiros do Estado para: analisar a relação de despesas com 
pessoal sobre as projeções de receita do Poder Executivo a partir de janeiro de 2015; avaliar a concessão de benefícios, gratificações e vantagens pessoais em exercício pretérito e emitir pareceres sobre o respectivo impacto financeiro no quadriênio 20152018; apresentar ao governador do Estado e seus auxiliares o panorama dos gastos com pessoal e o efeito a incidir sobre as receitas públicas; e auxiliar o governador do Estado nas medidas de adequação dos gastos com pessoal aos referenciais e limites previstos na legislação de regência.

Em novembro de 2016, foram anunciadas novas medidas de redução e controle de despesas do Executivo Estadual. Através delas o governo espera retornar ao limite da LRF até maio de 2017. O Decreto $n^{\circ} 5.532$, com vigência de cerca de cinco meses, trata das seguintes vedações: celebração de novos contratos, preenchimento de vagas ofertadas em concursos públicos, o pagamento de horas extras e diárias, exceto serviços de segurança, saúde e educação. Os ajustes também abrangem a demissão de aproximadamente dois mil servidores, entre eles, comissionados e contratados, sendo que a economia prevista é de 120 milhões nos próximos dois anos.

\subsubsection{PARAÍBA}

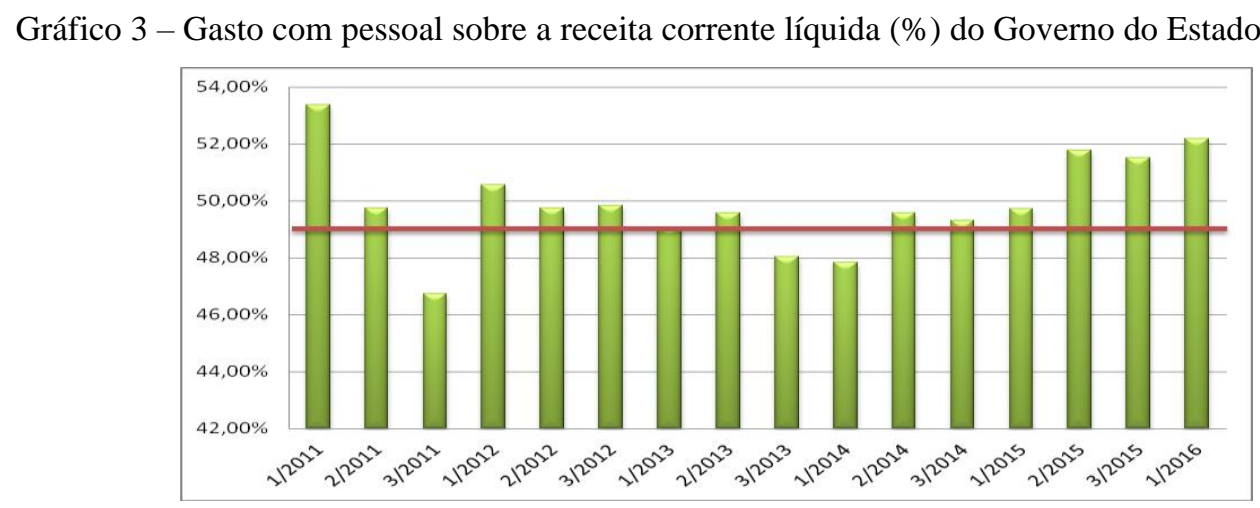

Fonte: elaborado segundo dados constantes no portal Compara Brasil (2016)

A Paraíba tem apresentado problemas em manter-se abaixo do limite máximo desde antes do início da série histórica apresentada no gráfico. O governo do Estado alegou que a relação entre a despesa total com pessoal e a receita corrente líquida foi prejudicada fortemente pela crise econômica mundial vivenciada ao longo do ano de 2009, aliada à queda de arrecadação e da transferência de recursos do Fundo de 


\section{COSTA; SILVA; ALVES DA SILVA; PINORI; BORGES; SANTOS}

Participação dos Estados (FPE), que suprimiu do orçamento previsto mais de R $\$ 280$ milhões em 2008. Além da isenção de impostos dos veículos automotivos e da chamada linha branca de eletrodomésticos, tudo decorrente de medidas vindas do Governo Federal para fazer face à crise econômica internacional que assolava no período. Ainda, contribuíram para o aumento do gasto do Poder Executivo a criação de 23 planos de cargos e salários ao final da gestão do governo anterior.

Por estar acima do limite máximo, o governo do Estado da Paraíba deveria ter sofrido as sanções impostas pela LRF para estados nesta condição. Entretanto, através de decisão liminar do Supremo Tribunal Federal - STF (AC 2588), as limitações impostas ao Estado da Paraíba foram suspensas.

No final de 2010, o então governador, Ricardo Coutinho, determinou algumas medidas com vistas a contribuir para o cumprimento do limite legal da despesa com pessoal do Estado, dentre as quais estão:

a) Redução da estrutura de cargos comissionados das administrações direta e indireta do Poder Executivo Estadual;

b) Redução do valor das gratificações de atividades especiais do Poder Executivo Estadual;

d) Acatamento das recomendações do Ministério Público Estadual no sentido da não renovação dos contratos de prestadores de serviços, que foram firmados em período proibitivo, em face da Lei de Responsabilidade Fiscal e Eleitoral;

e) Anulação dos atos editados nos últimos cento e oitenta dias de 2010, em respeito ao disposto no parágrafo único do art. 21 da Lei de Responsabilidade Fiscal.

A partir do último quadrimestre de 2011, verifica-se no Gráfico 3 que, de fato, o Estado atingiu o objetivo de retornar ao limite legal permitido pela lei. Entretanto, isso ocorreu apenas durante um período; nos próximos, a LRF foi novamente descumprida.

No $3^{\circ}$ quadrimestre de 2012, um novo pacote de medidas foi realizado com o objetivo de retorno ao limite. As providências foram adotadas no sentido de reduzir parcelas variáveis e redutíveis dos gastos com pessoal e encargos, a exemplo de horas extras e gratificações de atividades especiais; foi limitado o ingresso de servidores à reposição de quadros voltados à prestação de serviços essenciais para a população.

A partir do Gráfico 3 é possível constatar uma oscilação quanto à porcentagem da receita corrente líquida destinada aos gastos com pessoal. Observa-se que, segundo a 


\section{COSTA; SILVA; ALVES DA SILVA; PINORI; BORGES; SANTOS}

série histórica acima, o Estado da Paraíba sempre esteve acima do limite prudencial de $46,55 \%$.

A partir do segundo quadrimestre de 2014, as despesas com pessoal da Paraíba voltaram a atingir índices alarmantes novamente.

Com o intuito de reverter a crise que tem se alastrado por todo o país, estados da Região Nordeste lançaram, em 2015, pacotes econômicos com medidas acordadas entre eles e definidas em reuniões do Conselho Nacional de Secretários da Fazenda (Consefaz).

Essas medidas têm como finalidade conter gastos e, principalmente, aumentar a arrecadação. Na Paraíba, foram instituídos aumentos no IPVA, ICMS e ITCD; congelamento do salário do governador e de auxiliares; fusão e extinção de secretarias, diminuindo, dessa forma, o quadro de funcionários comissionados e contratados.

Em 2016, ano em que a despesa voltou a atingir a marca de mais de três pontos percentuais acima do limite máximo, o Tribunal de Contas da Paraíba decidiu, por meio do Ofício circular $n^{\circ}$ 010/2016, que os gestores de todos os órgãos públicos - estaduais e municipais - devem remeter ao TCE-PB a folha de pessoal de março do mesmo ano para um cruzamento de dados, em âmbito nacional, com a finalidade de verificar acumulação irregular de cargos públicos e recebimento de remuneração acima do teto constitucional.

\subsubsection{RIO GRANDE DO NORTE}

Gráfico 4 - Gasto com pessoal sobre a receita corrente líquida (\%) do Governo do Estado do Rio Grande do Norte

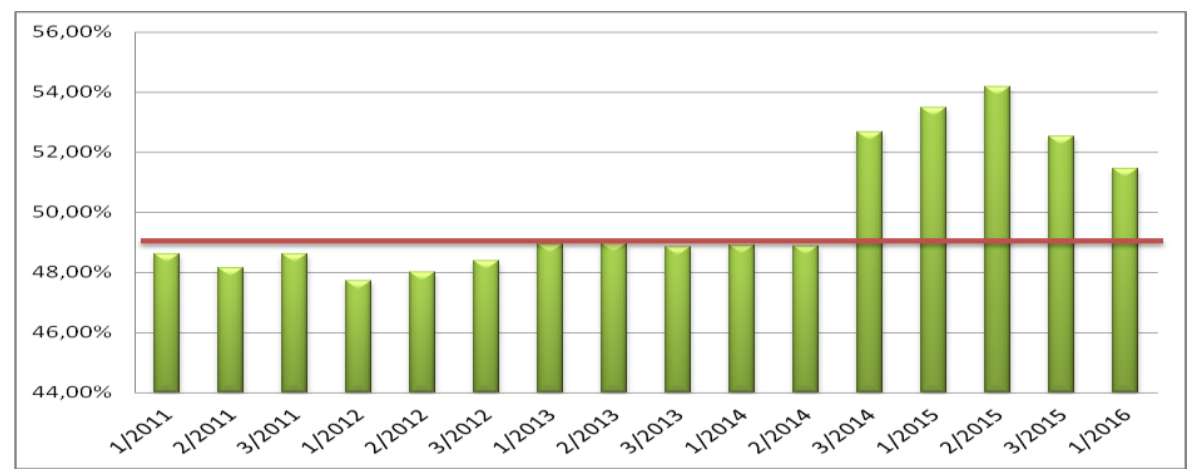

Fonte: elaborado segundo dados constantes no portal Compara Brasil (2016).

Os dados do Rio Grande do Norte são analisados a partir de 2011, quando o percentual 


\section{COSTA; SILVA; ALVES DA SILVA; PINORI; BORGES; SANTOS}

da despesa já ultrapassava o limite prudencial de gastos permitidos pela LRF (46,55\%). No final do ano de 2014, os gastos ultrapassaram o limite máximo permitido pela LRF, representado no gráfico pela linha vermelha.

Por ter ultrapassado o limite prudencial, o ente já estava sujeito a restrições que implicassem em aumento da despesa, tais como aumento ou reajuste da remuneração, criação de cargos, dentro outros.

No $3^{\circ}$ quadrimestre de 2014, o limite máximo foi ultrapassado. Conforme constante na LRF, o ente possui um prazo de até dois quadrimestres para adoção de medidas que visem à recondução aos limites. Este prazo teve fim no $2^{\circ}$ quadrimestre de 2015 . As medidas foram tomadas, motivo pelo qual o percentual da despesa apresentou um decréscimo; entretanto, até o $1^{\circ}$ quadrimestre de 2015, a despesa ainda não havia sido reconduzida ao limite.

Nas notas explicativas do RGF do $3^{\circ}$ quadrimestre de 2015, são apresentadas algumas providências que foram tomadas pelo governo do Rio Grande do Norte com vistas a diminuir as despesas com pessoal. Em análise ao Gráfico 2, percebe-se que as despesas de fato diminuíram. As providências foram as seguintes:

a) contratação da empresa Deloite Touche Tohmatsu para realizar auditoria na folha de pessoal ativo, inativos e pensionistas;

b) implementação de medidas saneadoras tais como: correção de parametrizações da folha de pagamento que geravam distorções; revisão de procedimentos que se encontravam em desacordo com a legislação em vigor; anulação de acumulação indevida de cargos; exclusão da percepção indevida de adicionais; e ajuste da remuneração de servidores que se encontravam em desacordo com a lei, gerando pagamento indevido de abono, dentre outras vantagens;

c) implementação de procedimento de controle e acompanhamento de frequência, controle de profissionais da saúde e análise dos pontos e frequência de servidores que percebiam adicional noturno;

d) análise de aposentadorias concedidas em desconformidade com os dispositivos legais;

e) exame das aposentadorias compulsórias;

f) verificação de informações de óbito em cotejo com situação de pensionistas com exclusão de benefícios pagos ilegalmente; 
g) realização do CENSO do servidor público para eliminar eventuais distorções e/ou pagamentos indevidos;

h) contratação de programa de reforma do Estado tendo por objetivo a redução do dispêndio de pessoal, a identificação de funções sobrepostas e a otimização da atividade institucional do Estado; a iniciativa se encontra em andamento através de contrato firmado com o Instituto PUBLIX, organização com efetiva e positiva participação em projetos de reforma e modernização das administrações públicas dos Estados de Minas Gerais e Pernambuco, entre outros trabalhos desenvolvidos para instituições públicas;

i) desenvolvimento de controles na concessão e apuração de horas extras no âmbito da administração do Poder Executivo;

j) análise do impacto das decisões judiciais no total da despesa com pessoal e encargos (em curso), cujo montante deve ser subtraído do cômputo de gastos com pessoal, conforme a legislação de regência.

As providências tomadas obtiveram o efeito esperado. Já no primeiro quadrimestre de 2016, o Governo do Estado do RN economizou R\$ 95 milhões com relação ao mesmo quadrimestre de 2015; entretanto, o objetivo principal, que é retornar ao limite máximo permito pela LRF (49\%), ainda não foi atingido.

\subsubsection{ACRE}

Gráfico 5 - Gasto com pessoal sobre a receita corrente líquida (\%) do Governo do Estado do Acre

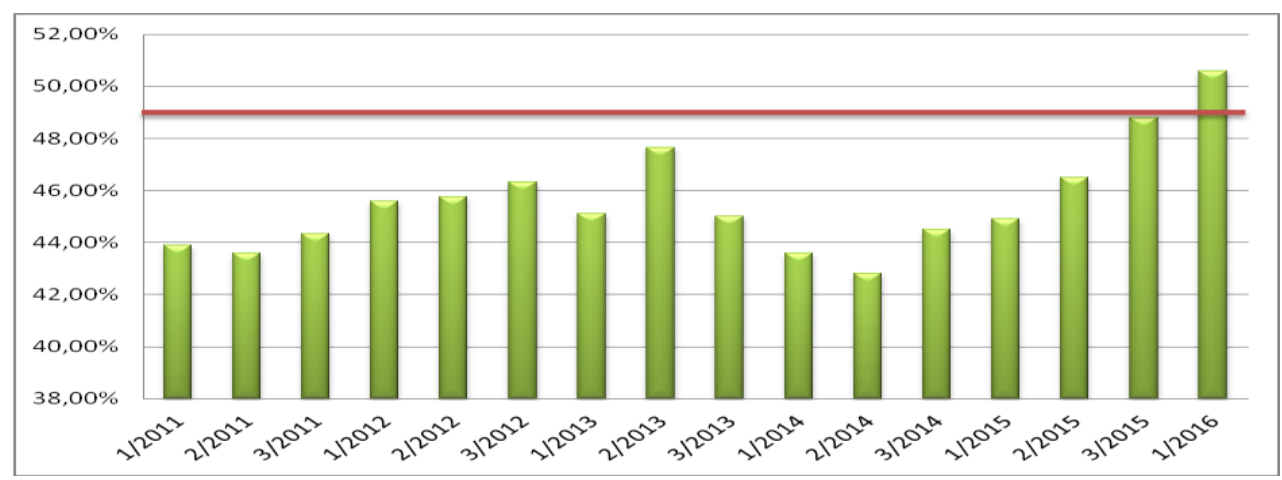

Fonte: elaborado segundo dados constantes no portal Compara Brasil (2016).

Observa-se que, no $2^{\circ}$ quadrimestre de 2013, houve o primeiro pico do percentual de gastos com pessoal no Acre, o qual serviu de alerta para que, em 2014, fosse instituída uma minirreforma administrativa para reorganizar os cargos e garantir a redução 
orçamentária. Dentre as medidas aprovadas pela Assembleia Legislativa do Estado está a decisão de manter os 940 cargos comissionados, vedando o aumento do quantitativo desse tipo de cargo. Acrescido ainda de medidas de redução de 16 cargos de diretoria e outros de assessorias e coordenadorias.

De fato, nos três quadrimestres seguintes houve uma redução do percentual de gastos com pessoal que era consumido da receita corrente líquida. Entretanto, a partir do $3^{\circ}$ quadrimestre de 2014 houve um constante aumento que saiu de uma situação de apenas alerta para uma efetiva extrapolação do limite máximo legal, de $49 \%$, no $1^{\circ}$ quadrimestre de 2016.

O Tribunal de Contas do TCE, através da Resolução nº 102, de 28 de abril de 2016, regulamentou o Sistema de Controle de Atos de Pessoal (SICAP) com o objetivo de coletar a analisar informações sobre a folha de pagamento das entidades jurisdicionadas. Tal sistema permitirá ao TCE-Acre celeridade na detecção de irregularidades.

\subsubsection{MATO GROSSO}

\section{Gráfico 6 - Gasto com pessoal sobre a receita corrente líquida (\%) do Governo do Estado do Mato} Grosso

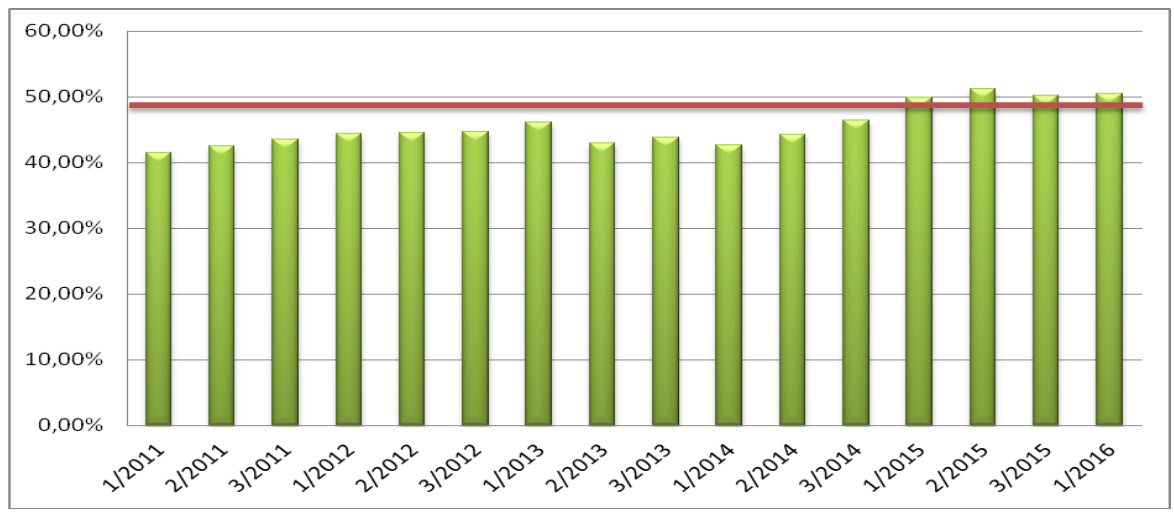

Fonte: elaborado segundo dados constantes no portal Compara Brasil (2016).

No $3^{\circ}$ quadrimestre de 2014, o Mato Grosso atingiu o alerta quanto à observância dos limites estabelecidos; apresenta um constante crescimento da proporção dos gastos com pessoal frente à receita corrente líquida. Segundo o secretário do Estado, o grande problema está justamente no aumento desproporcional de receitas e despesas, no qual as despesas crescem numa proporção maior do que se consegue arrecadar como receita. 
Dessa forma, no $1^{\circ}$ quadrimestre de 2015 , houve o rompimento do limite máximo, situação mantida nos quadrimestres seguintes.

O estado do Mato Grosso esclarece que para regularizar sua situação conta com a entrada de novas receitas, como o pagamento do FEX 2016 - um auxílio financeiro para fomento das exportações vindos do Governo Federal. Cita ainda como medida a renúncia de incentivos fiscais e também os valores a serem arrecadados pelo Comitê Interinstitucional de Recuperação de Ativos (Cira). O secretário de Estado de Gestão, em reportagem divulgada no site do governo do Mato Grosso, afirma que a entrada de recursos é fundamental para que o Estado consiga fechar o ano de 2016 dentro do limite estabelecido na LRF para gastos com pessoal.

Outro ponto destacado pelo secretário para a reversão da situação econômica do Estado é a adoção do chamado Pacto por Mato Grosso, o qual tem como medidas a redução de duodécimo dos poderes, corte de incentivos fiscais, renegociação da dívida da União, debates com o setor produtivo sobre o novo Fundo Estadual de Transporte e Habitação (Fethab) e redução de despesas de custeio e de folha por meio da instauração de uma futura reforma administrativa.

\subsection{COMPILAÇÃO DAS MEDIDAS TOMADAS}

O quadro a seguir mostra a compilação das medidas tomadas identificadas. Elas foram obtidas através de notícias, decretos, informações dos tribunais de contas e dados fornecidos nos relatórios de gestão fiscal.

Quadro 2 - Quadro resumo das principais medidas tomadas pelos estados

\begin{tabular}{|l|l|}
\hline \multirow{5}{*}{ Estado } & \multicolumn{1}{c|}{ Medidas tomadas } \\
\hline \multirow{5}{*}{ Tocantins } & Reestruturação da organização do Poder Executivo. \\
\cline { 2 - 3 } & Demissão de servidores comissionados e contratados. \\
\cline { 2 - 3 } & Extinção de cargos comissionados. \\
\cline { 2 - 3 } & Redução dos salários dos ocupantes de cargos comissionados. \\
\cline { 2 - 3 } & $\begin{array}{l}\text { Comissão de Análise de Impacto de Pessoal sobre os Recursos Financeiros do Estado } \\
\text { para analisar a relação de despesas com pessoal sobre as projeções de receita do Poder } \\
\text { Executivo; avaliar a concessão de benefícios, gratificações e vantagens pessoais em } \\
\text { exercício pretérito e emitir pareceres sobre o respectivo impacto financeiro no quadriênio } \\
\text { 2015-2018. }\end{array}$ \\
\cline { 2 - 3 } & Vedação da celebração de novos contratos. \\
\cline { 2 - 3 } & Vedação do preenchimento de vagas ofertadas em concursos públicos. \\
\cline { 2 - 3 } & Vedação de pagamento de horas extras e diárias, exceto serviços de segurança, saúde e \\
& eduçação. \\
\hline
\end{tabular}




\begin{tabular}{|c|c|}
\hline \multirow{8}{*}{ Paraíba } & $\begin{array}{l}\text { Redução da estrutura de cargos comissionados das administrações direta e indireta do } \\
\text { Poder Executivo Estadual. }\end{array}$ \\
\hline & Redução do valor das gratificações de atividades especiais do Poder Executivo Estadual. \\
\hline & $\begin{array}{l}\text { Não renovação dos contratos de prestadores de serviços, que foram firmados em período } \\
\text { proibitivo, em face da Lei de Responsabilidade Fiscal e Eleitoral. }\end{array}$ \\
\hline & Redução de parcelas variáveis e redutíveis, como hora extra e gratificações. \\
\hline & Aumentos nas alíquotas do IPVA, ICMS e ITCD. \\
\hline & Congelamento do salário do governador e de auxiliares. \\
\hline & $\begin{array}{l}\text { Fusão e extinção de secretarias, diminuindo, dessa forma, o quadro de funcionários } \\
\text { comissionados e contratados. }\end{array}$ \\
\hline & $\begin{array}{l}\text { Cruzamento de dados, em âmbito nacional, com a finalidade de verificar acumulação } \\
\text { irregular de cargos públicos e recebimento de remuneração acima do teto constitucional. }\end{array}$ \\
\hline \multirow{10}{*}{$\begin{array}{l}\text { Rio Grande do } \\
\text { Norte }\end{array}$} & $\begin{array}{l}\text { Contratação da empresa Deloite Touche Tohmatsu para realizar auditoria na folha de } \\
\text { pessoal ativo, inativos e pensionistas. }\end{array}$ \\
\hline & $\begin{array}{l}\text { Implementação de medidas saneadoras tais como: correção de parametrizações da folha } \\
\text { de pagamento que geravam distorções; revisão de procedimentos que se encontravam em } \\
\text { desacordo com a legislação em vigor; anulação de acumulação indevida de cargos; } \\
\text { exclusão da percepção indevida de adicionais; e, ajuste da remuneração de servidores que } \\
\text { se encontravam em desacordo com a lei, gerando pagamento indevido de abono, dentre } \\
\text { outras vantagens; }\end{array}$ \\
\hline & $\begin{array}{l}\text { Implementação de procedimento de controle e acompanhamento de frequência, controle } \\
\text { de profissionais da saúde e análise dos pontos e frequência de servidores que percebiam } \\
\text { adicional noturno. }\end{array}$ \\
\hline & Análise de aposentadorias concedidas em desconformidade com os dispositivos legais. \\
\hline & Exame das aposentadorias compulsórias. \\
\hline & $\begin{array}{l}\text { Verificação de informações de óbito em cotejo com situação de pensionistas com } \\
\text { exclusão de benefícios pagos ilegalmente. }\end{array}$ \\
\hline & $\begin{array}{l}\text { Realização do CENSO do Servidor Público para eliminar eventuais distorções e/ou } \\
\text { pagamentos indevidos. }\end{array}$ \\
\hline & $\begin{array}{l}\text { Contratação de programa de reforma do Estado tendo por objetivo a redução do } \\
\text { dispêndio de pessoal, a identificação de funções sobrepostas e a otimização da atividade } \\
\text { institucional do Estado; a iniciativa se encontra em andamento através de contrato } \\
\text { firmado com o Instituto PUBLIX. }\end{array}$ \\
\hline & $\begin{array}{l}\text { Desenvolvimento de controles na concessão e apuração de horas extras no âmbito da } \\
\text { administração do Poder Executivo. }\end{array}$ \\
\hline & $\begin{array}{l}\text { Análise do impacto das decisões judiciais no total da despesa com pessoal e encargos (em } \\
\text { curso), cujo montante deve ser subtraído do cômputo de gastos com pessoal, conforme a } \\
\text { legislação de regência. }\end{array}$ \\
\hline \multirow[b]{3}{*}{ Acre } & Vedação de aumento quantitativo de cargos comissionados. \\
\hline & Redução de cargos de diretoria e outros de assessorias e coordenadorias. \\
\hline & $\begin{array}{l}\text { Regulamentação do TCE-Acre do Sistema de Controle de Atos de Pessoal (SICAP) com } \\
\text { o objetivo de coletar e analisar informações sobre a folha de pagamento das entidades } \\
\text { jurisdicionadas. }\end{array}$ \\
\hline Mato Grosso & $\begin{array}{l}\text { Adoção do chamado Pacto por Mato Grosso, o qual tem como medidas a redução de } \\
\text { duodécimo dos poderes, corte de incentivos fiscais, renegociação da dívida da União, } \\
\text { debates com o setor produtivo sobre o novo Fundo Estadual de Transporte e Habitação } \\
\text { (Fethab) e redução de despesas de custeio e de folha por meio da instauração de uma } \\
\text { futura reforma administrativa. }\end{array}$ \\
\hline
\end{tabular}

Fonte: elaborado com base nos dados obtidos.

Diminuir gastos com pessoal no setor público é algo impopular, visto que envolve milhares de servidores públicos da administração pública. A grande maioria desses servidores na literatura da área de ciência política são chamados "burocratas de nível de 


\section{COSTA; SILVA; ALVES DA SILVA; PINORI; BORGES; SANTOS}

rua", ou seja, são eles que têm contato direto com a sociedade. Desta forma, as medidas identificadas nesta investigação provocam um efeito que pode contribuir para reduzir a folha de pagamento, mas também pode impactar na garantia da manutenção do bemestar social. Os Estados precisam tomar decisões impopulares e lidar com a ira da população para retornar à regularidade, por isso, voltar ao limite estabelecido pela LRF é tarefa árdua e que não pode ser realizada de uma hora para outra; seus impactos poderiam prejudicar muitas pessoas e famílias.

As medidas mais populares entre os Estados abordados envolvem a redução de cargos comissionados e congelamento ou redução de salários. É possível notar também que existem medidas inovadoras, como a contratação de uma empresa de auditoria externa para certificar a regularidade dos gastos.

\section{CONSIDERAÇÕES FINAIS}

A despesa com pessoal é um tema bastante relevante no cenário atual. Mesmo com 16 anos de LRF, alguns Estados ainda não conseguiram se adequar aos limites estabelecidos pela Lei, o que acarreta em várias sanções para o Estado e também em uma série de medidas impopulares para que ele possa voltar ao limite.

Considerando esse contexto e o cenário econômico atual, o presente estudo teve por objetivo geral verificar o que os Estados com os maiores gastos com pessoal estão adotando como medida para reduzir seus gastos e voltar ao limite permitido pela LRF. Também se buscou realizar uma análise histórica dos gastos com pessoal dos Estados em questão, identificando as sanções previstas, assim como as medidas tomadas pelo gestor do Estado.

Através de dados fornecidos pelo SICONFI, foi possível observar que cinco Estados estavam acima do limite máximo de pessoal permitido ao Poder Executivo Estadual na LRF no início de 2016, o que os tornou objeto desse estudo; são eles: Tocantins, Paraíba, Rio Grande do Norte, Acre e Mato Grosso.

Pela análise histórica dos Estados, pode-se observar que as despesas com pessoal foram crescendo ao longo do tempo, mesmo com os limites estabelecidos pela LRF. Alguns deles conseguiram diminuir seus gastos com as medidas adotadas, mas apenas por um certo período.

Esperava-se encontrar medidas impopulares nos Estados, como demissões e reduções de 
salários e aumento dos impostos, o que foi observado; as medidas mais populares entre os Estados abordados envolvem a redução de cargos comissionados e congelamento ou redução de salários. Mas também pode-se notar que os Estados estão buscando medidas paliativas que não prejudiquem diretamente os funcionários da administração pública, como a contratação de uma empresa de auditoria para garantir a regularidade dos gastos. Portanto, conclui-se que os Estados abordados, apesar de estarem acima do limite imposto pela LRF para gasto com pessoal, estão implementando medidas para adequar seus gastos e retornar às exigências da Lei de Responsabilidade Fiscal e já é visível o efeito dessas medidas, como pode ser observado na análise histórica do Rio Grande do Norte, que vem apresentando uma diminuição na porcentagem de gastos com pessoal na composição da receita líquida, e na análise do Mato Grosso que, apesar de não reduzir o percentual dos gastos, está mantendo-o estável.

O presente estudo fez uma análise dos Estados com maior percentual de despesa total com pessoal do Poder Executivo Estadual. Nesse sentido, sugere-se novas pesquisas que busquem analisar a situação de outros Estados que também apresentam deficiência no controle dos gastos com pessoal, assim como a análise da despesa com pessoal dos Poderes Legislativo e Judiciário. Ressalta-se aqui a dificuldade de obtenção das medidas tomadas pelos Estados, o que é uma limitação deste estudo.

\section{REFERÊNCIAS}

ANDRADE, T. Tribunal de Contas confirma que concessão do RGA impacta na LRF. Governo do Mato Grosso, Gcom-MT 21 jun. 2016. Disponível em: http://www.mt.gov.br/-/4356368-tribunal-de-contas-confirma-que-concessao-do-rgaimpacta-na-lrf. Acesso em: 16 out. 2016.

BRASIL. Lei $\mathbf{n}^{\mathbf{0}}$ 4.320, de 17 de março de 1964. Estatui Normas Gerais de Direito Financeiro para elaboração e controle dos orçamentos e balanços da União, dos Estados, dos Municípios e do Distrito Federal. Brasília, DF, 1964. Disponível em: http://www.planalto.gov.br/ccivil_03/leis/L4320.htm. Acesso em: 10 maio 2016.

Decreto-lei $n^{0}$ 201, de 27 de fevereiro de 1967. Dispõe sobre a responsabilidade dos Prefeitos e Vereadores, e dá outras providências. Brasília, DF, 1967. Disponível em: http://www.planalto.gov.br/ccivil_03/decreto-lei/Del0201.htm. Acesso em: 17 maio 2016.

[Constituição (1988)]. Constituição da República Federativa do Brasil: promulgada em 5 de outubro de 1988. Brasília, DF, 1988. Disponível em: http://www.planalto.gov.br/ccivil_03/constituicao/constituicao.htm. Acesso em: 12 
maio 2016.

Lei $\mathbf{n}^{0}$ 10.028, de 19 de outubro de 2000. Altera o Decreto-Lei no 2.848, de 7 de dezembro de 1940 - Código Penal, a Lei no 1.079, de 10 de abril de 1950, e o Decreto-Lei no 201, de 27 de fevereiro de 1967. Brasília, DF, 2000a. Disponível em: http://www.planalto.gov.br/ccivil_03/leis/L10028.htm. Acesso em: 17 maio 2016.

Lei complementar $n^{0}$ 101, de 4 de maio de 2000. Estabelece normas de finanças públicas voltadas para a responsabilidade na gestão fiscal e dá outras providências. Brasília, DF, 2000b. Disponível em: http://www.planalto.gov.br/ccivil_03/leis/LCP/Lcp101.htm. Acesso em: 10 maio 2016.

. Ministério da Fazenda. Secretaria do Tesouro Nacional. Manual de

Demonstrativos Fiscais: Aplicado à União e aos Estados, Distrito Federal e Municípios. Brasília, 2014.

BRASIL. Ministério da Fazenda. Secretaria do Tesouro Nacional. Despesa com Pessoal. Disponível em: http://www3.tesouro.fazenda.gov.br/series_temporais/. Acesso em: 8 maio 2016.

BRASIL. Ministério da Fazenda. Secretaria do Tesouro Nacional. Infrações da Lei de Responsabilidade Fiscal e suas penalidades. Disponível em:

http://www.tesouro.fazenda.gov.br/-/infracoes-da-lei-de-responsabilidade-fiscal-e-suaspenalidades. Acesso em: 18 maio 2016.

BRASIL. Ministério da Fazenda. Secretaria do Tesouro Nacional. Lei de

Responsabilidade Fiscal. Disponível em: http://www.tesouro.fazenda.gov.br/pt_PT/leide-responsabilidade-fiscal. Acesso em: 20 maio 2016.

CAMARGO, M. E.; SEHNEM, A. Efeitos da Lei de Responsabilidade Fiscal sobre a Prestação de Contas das Prefeituras Catarinenses. RACE, Unoesc, Joaçaba, v. 9, n. 1-2, p. 251-272, jan./dez. 2010.

COMPARA BRASIL. Gastos com Pessoal. Disponível em:

http://comparabrasil.com/comparabrasil/estados/Paginas/planilhaEstado.aspx?g=4.

Acesso em: 2 nov. 2016.

CORREIA, A. F.; FlAMMARION, E. P.; VALLE, V. R. L. do. Despesa de Pessoal: A Chave da Gestão Fiscal Responsável: teoria e prática. Rio de Janeiro: Forense, 2001.

DANCHURA, D. Governo fecha gastos com pessoal em 50,46\% no primeiro quadrimestre. Governo do Mato Grosso, Seges-MT, 07 jun. 2016. Disponível em: http://www.mt.gov.br/-/4280525-governo-fecha-gastos-com-pessoal-em-50-46-noprimeiro-quadrimestre. Acesso em: 16 out. 2016.

DANTAS, P. Mau humor econômico: estados do NE lançam pacotes para superar crise. Revista Nordeste, Brasil, 27 nov. 2015. Disponível em:

http://revistanordeste.com.br/noticia/mau-humor-economico-estados-do-ne-lancampacotes-para-superar-crise/. Acesso em: 16 out. 2016.

DIAS, F. A. C. O controle institucional das despesas com pessoal. Brasília, DF: Centro de Estudos da Consultoria do Senado Federal, 2009. Disponível em: https://www12.senado.leg.br/publicacoes/estudos-legislativos/tipos-de-estudos/textospara-discussao/td-54-o-controle-institucional-das-despesas-com-pessoal. Acesso em: 14 maio 2016.

Revista Eletrônica Gestão e Serviços v.10, n. 1, pp. 2556 - 12581aneiro/Junho 2019.

ISSN Online: 2177-7284 e-mail: regs@metodista.br 
GIACOMONI, J. Orçamento Público. 16. ed. São Paulo: Atlas, 2012.

GIL, A. C. Metodologia do ensino superior. $2^{\mathrm{a}}$ ed. São Paulo: Atlas, 2002.

GONÇALVES, T. Tribunal de Contas apresenta SICAP. Rio Branco: Assessoria de Comunicação, Tribunal de Contas do Estado do Acre, 2016. Disponível em:

http://www.tce.ac.gov.br/2016/06/10/tribunal-de-contas-apresenta-sicap/. Acesso em: 10 nov. 2016.

LIMA, D. V.; CASTRO, R. G. Contabilidade Pública. 3. ed. São Paulo: Atlas, 2009.

LUQUE, C. A.; SILVA, V. M. A Lei de Responsabilidade na Gestão Fiscal:

Combatendo Falhas de Governo à Brasileira. Revista de Economia Política, São

Paulo, v. 24, n. 3(95), p. 404-421, jul./set. 2004. Disponível em:

http://www.rep.org.br/PDF/95-6.PDF. Acesso em: 19 maio 2016.

MACÊDO, F. F. R. R; MACHADO, M.V.V; SCARPIN, J.E. Controle Interno no Setor Público: estudo em uma prefeitura do interior do Ceará sob a ótica da Instrução

Normativa, n. 1, 1997 do Tribunal de Contas dos Municípios do Estado do Ceará, 2014. Disponível em: <http://www.ipea.gov.br/ppp/index.php/PPP/article/view/323>. Acesso em: 10 mai. 2018.

NASCIMENTO, E. R. A Lei de Responsabilidade Fiscal e a Polêmica das Despesas com Pessoal. Brasília, DF, ago. 2003. Disponível em:

http://www.bndes.gov.br/SiteBNDES/export/sites/default/bndes_pt/Galerias/Arquivos/b f_bancos/e0001950.pdf. Acesso em: 14 maio 2016.

PARAÍBA. Governo do Estado. Controladoria Geral do Estado. Relatórios da Gestão Fiscal. Disponível em: http://www.siaf.cge.pb.gov.br/. Acesso em: 10 nov. 2016.

PLATT NETO, O. A. et al. Publicidade e Transparência das Contas Públicas: obrigatoriedade e abrangência desses princípios na administração pública brasileira.

Contabilidade Vista \& Revista, v. 18, n. 1, p. 75-94, jan./mar. 2007. Disponível em: http://revistas.face.ufmg.br/index.php/contabilidadevistaerevista/article/view/320.

Acesso em: 19 maio 2016.

POJO, Ana Paula. Minirreforma administrativa reorganiza cargos e garante redução orçamentária. Agência Acre, 16 dez. 2014. Disponível em:

http://www.agencia.ac.gov.br/minirreforma-administrativa-reorganiza-cargos-e-garantereducao-orcamentaria/. Acesso em: 15 out. 2016.

SANTOLIN, R.; JAYME JÚNIOR, F. G.; REIS, J. C. dos. Lei de Responsabilidade Fiscal e implicações na despesa de pessoal e de investimento nos municípios mineiros: um estudo com dados em painel dinâmico. Estudos Econômicos, São Paulo, v. 39, n. 4, out./dez. 2009.

SILVA, C. C. S. da; SILVA, R. F. Despesas públicas - despesa com pessoal. Ariquemes: Faculdades Integradas de Ariquemes - FIAR, 2011. Disponível em: http://www.jurisway.org.br/v2/dhall.asp?id_dh=5490. Acesso em: 14 maio 2016.

SOUZA, P. de; PLATT NETO, O. A. A composição e a evolução das despesas com pessoal do Estado de Santa Catarina de 2000 a 2011. Trabalho apresentado no XIX Congresso Brasileiro de Custos, Bento Gonçalves, RS, Brasil, 2012.

SOUZA, R. S. de. Despesa de pessoal segundo a lei de responsabilidade fiscal.

Revista Eletrônica Gestão e Serviços v.10, n. 1, pp. 2556 - 12581aneiro/Junho 2019.

ISSN Online: 2177-7284 e-mail: regs@ metodista.br 
Florianópolis: Universidade Federal de Santa Catarina - UFSC, 2004. Disponível em: http://tcc.bu.ufsc.br/Contabeis300704. Acesso em: 14 maio 2016.

TOCANTINS. Medida Provisória ${ }^{\circ}$ 12, de 2 de agosto de 2013. Reorganiza os cargos de provimento em comissão e as funções de confiança que especifica da estrutura organizacional do Poder Executivo, e adota outras providências. Diário Oficial do Estado do Tocantins, Palmas, TO, 5 ago. 2013, n 3.931.

Decreto $n^{\circ}$ 5.184, de $1^{\circ}$ de janeiro de 2015. Institui a Comissão de Análise de Impacto de Pessoal sobre os Recursos Financeiros do Estado, e adota outras providências. Diário Oficial do Estado do Tocantins, Palmas, TO, 2 jan. 2015, n 4.288.

Lei de Responsabilidade Fiscal já ameaça 20 Estados; Tocantins é o segundo que mais gasta com pessoal. Conexão Tocantins, 10 fev. 2016. Disponível em: http://conexaoto.com.br/2016/02/10/lei-de-responsabilidade-fiscal-ja-ameaca-20estados-tocantins-e-o-segundo-que-mais-gasta-com-pessoal. Acesso em: 27 ago. 2016.

TRIBUNAL DE CONTAS DO ESTADO DA PARAÍBA. TCE-PB solicita aos gestores públicos folha de pessoal para cruzamento de dados. Ascom TCE-PB, Paraíba, abr. 2016. Disponível em: http://portal.tce.pb.gov.br/2016/04/tce-pb-solicitaaos-gestores-publicos-folha-de-pessoal-para-cruzamento-de-dados/. Acesso em: 16 out. 2016.

VALLE, B. S.; TORRES, F. R. Impactos sobre a Despesa com Pessoal dos Estados Brasileiros em Decorrência da LRF. Trabalho apresentado no XXXII Encontro da ANPAD. Rio de Janeiro, 6 a 10 de setembro de 2008.

VERÍSSIMO, V. Medidas de contenção de gastos são anunciadas pelo governador Marcelo Miranda. Governo do Tocantins, Portal do Tocantins, 10 nov. 2016. Disponível em: http://to.gov.br/noticia/2016/11/10/medidas-de-contencao-de-gastossao-anunciadas-pelo-governador-marcelo-miranda/. Acesso em: 10 nov. 2016.

ZONATTO, V. C. da S.; RODRIGUES JUNIOR, M. M.; TOLEDO FILHO, J. R. Aplicação do Modelo de KOYCK na Previsão de Receitas Públicas: Uma Análise das Previsões Orçamentárias Realizadas pelos 10 Maiores Municípios em População no Estado do Rio Grande do Sul. RACE, Unoesc, Joaçaba, v. 13, n. 1, p. 249-276, jan./abr. 2014. 